\title{
Lung torsion: Some answers but more questions
}

\author{
Benjamin Wei, MD
}

\footnotetext{
From the Division of Cardiothoracic Surgery, Department of Surgery, University of Alabama Birmingham School of Medicine, Birmingham, Ala.

Disclosures: Author has nothing to disclose with regard to commercial support.

Received for publication April 21, 2016; accepted for publication April 26, 2016; available ahead of print May 20 , 2016.

Address for reprints: Benjamin Wei, MD, Division of Cardiothoracic Surgery, Department of Surgery, University of Alabama Birmingham School of Medicine, ZRB 739, 1720 2nd Ave S, Birmingham, AL 35294-0007 (E-mail: bwei@uab.edu).

J Thorac Cardiovasc Surg 2016;152:658

0022-5223/\$0.00

Published by Elsevier Inc. on behalf of The American Association for Thoracic Surgery http://dx.doi.org/10.1016/j.jtcvs.2016.04.077
}

Lung torsion (LT) after pulmonary surgery is an exceedingly rare event, but it can be catastrophic when it occurs. In one large retrospective study, the risk of LT requiring surgical reintervention was fewer than 1 in 1000 patients. ${ }^{1}$ Surgeons differ with regard to whether anything can or should be done to prevent this complication. Various methods have been proposed for preventing LT, with a focus on preventing middle lobe torsion after right upper lobectomy by fixing the middle lobe to the lower lobe with suture, stapling, glues, and even pleural flaps. ${ }^{2-4}$ The efficacy of any specific technique has not been verified, however, because of the rarity with which LT occurs. The treatment for LT has also been difficult to study because of this rarity.

The contribution of Dai and colleagues ${ }^{5}$ in this issue of The Journal is therefore especially helpful. This review of 109 patients from 91 studies, spanning the years 1950 through 2014, represents the largest accumulation of patients with LT in the literature. The work of Dai and colleagues ${ }^{5}$ supports the impression that the right middle lobe is the most commonly affected $(37.5 \%$ of postoperative LT cases). Perhaps more illuminating, though, is the fact that $62.5 \%$ of postresection torsions involved other lobes. Furthermore, $20 \%$ of patients with LT had no symptoms, and LT went misdiagnosed or undiagnosed $40 \%$ of the time, demonstrating the need to be vigilant about this complication after any anatomic lung resection. Although Dai and colleagues ${ }^{5}$ found that the time to diagnosis was a median of 3 days after lung resection, the etiology and time course of LT remain unknown (does it happen suddenly or gradually? what precipitates it?), as do patient and intraoperative and postoperative risk factors for its occurrence.

The algorithm of Dai and colleagues ${ }^{5}$ for evaluation of suspected LT uses an initial radiograph as a screening tool, followed by bronchoscopy or computed tomographic scan. If bronchoscopy demonstrates a narrowed or distorted bronchus orifice, or if the computed tomographic scan shows bronchial or vascular truncation or malposition,

\section{References}

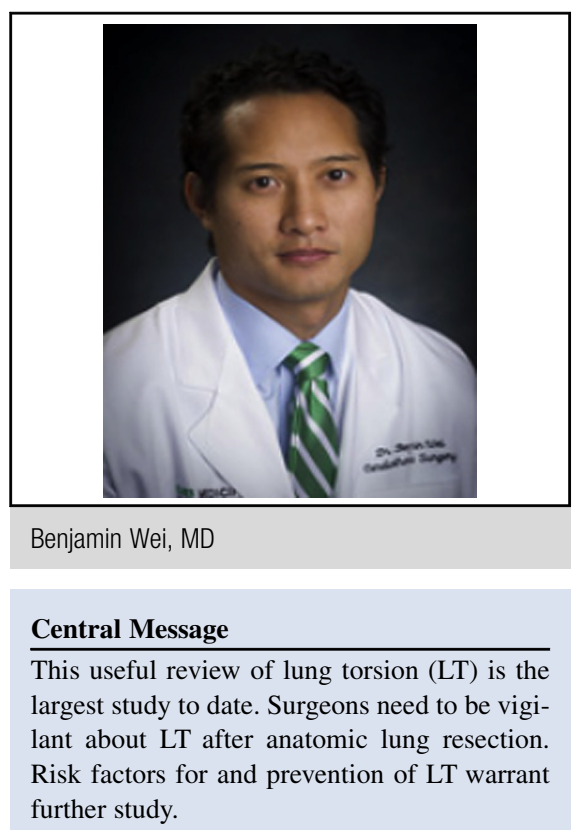

See Article page 737 .

See Editorial Commentary page 746.

surgical intervention should be expeditious. Dai and colleagues 5 favor "direct" resection (without detorsion of the lung) in cases where the lung is infarcted, and they condone repositioning the lobe instead if it appears viable. Reassuringly, the overall mortality after LT was $8.3 \%$, and it appears to have decreased with time, although these findings may be susceptible to publication bias. This study provides useful details about the characteristics and treatment of LT, but the questions of whether this complication should or can be prevented and how to best accomplish this still linger, and likely will do so for the foreseeable future.

1. Cable DG, Deschamps C, Allen MS, Miller DL, Nichols FC, Trastek VF, et al. Lobar torsion after pulmonary resection: presentation and outcome. J Thorac Cardiovasc Surg. 2001;122:1091-3.

2. Kutlu CA, Olgac G. Pleural flap to prevent lobar torsion: a novel technique. Eur J Cardiothorac Surg. 2006;30:943-4.

3. Uramoto H, Takenoyama M, Hanagiri T. Simple prophylactic fixation for lung torsion. Ann Thorac Surg. 2010;90:2028-30.

4. Purohit M, Zacharias J. A simple reproducible method of preventing lobar torsion. J Cardiothorac Surg. 2008;3:22.

5. Dai J, Xie D, Wang H, He W, Zhou Y, Hernández-Arenas LA, et al. Predictors of survival in lung torsion: a systematic review and pooled analysis. J Thorac Cardiovasc Surg. 2016;152:737-45.e3. 